ESJ Social Sciences

\title{
Adoption of Brain-Based Instruction by Higher Education Science and Engineering Departments in Ethiopia: A Quantitative and Qualitative Survey
}

\author{
Ataklti Abraha \\ Ph.D. student, School of Education, Huazhong University of Science and \\ Technology (HUST), Wuhan Hubei, P. R. China

\section{Luo Siming} \\ Professor, School of Education, Huazhong University of Science and \\ Technology (HUST), Wuhan Hubei, P. R. China
}

Doi:10.19044/esj.2021.v17n5p91

Submitted: 21 October 2020

Accepted: 12 February 2021

Published: 28 February 2021
Copyright 2021 Author(s)

Under Creative Commons BY-NC-ND

4.0 OPEN ACCESS

Cite As:

Abraha A. \& Siming L. (2021). Adoption of Brain-Based Instruction by Higher Education Science and Engineering Departments in Ethiopia: A Quantitative and Qualitative Survey. European Scientific Journal, ESJ, 17(5), 91.

https://doi.org/10.19044/esj.2021.v17n5p91

\section{Abstract}

Brain-Based Instruction methods have become influential at almost all educational levels. This paper examined the extent to which Natural and Computational Sciences and Engineering instructors in Ethiopian Higher Education Institutions apply Brain-Based Instruction principles (i.e., relaxed alertness, orchestrated immersion, and active processing) in their learningteaching process. This paper used a descriptive survey research design with a concurrent mixed (quantitative and qualitative) methodology. A questionnaire was used to gather quantitative data from a random sample of 512 instructors (292 from Natural and Computational Sciences and 220 from Engineering). Qualitative data were gathered from six selected instructors (three from Natural and Computational Sciences and three from Engineering) via a semistructured interview. A pilot study was used to confirm the validity and reliability of the research instruments. Quantitative data were analyzed by standard univariate methods. Qualitative data were analyzed by thematic analysis. The findings depicted that limited implementation of Brain-Based Instruction principles. Furthermore, the study showed that Higher Diploma Program training and length of teaching experience positively influenced the 
use of Brain-Based Instruction principles. The paper discusses implications for Brain-Based Instruction in Ethiopia and suggests areas for future research.

Keywords: Brain-Based Instruction; classroom practices; implementation differences; Higher Diploma Program training; Ethiopia; engineering, natural sciences

\section{Introduction}

In the past two decades, educators and researchers have been influenced by brain research on how the human brain learns, and have begun to apply these insights to improving classroom educational practices (Renate Nummela Caine, Caine, McClintic, \& Klimek, 2005; E. P. Jensen, 2008; J. N. Zadina, 2015). The search for better instructional methods has harnessed research from cognitive neuroscience, neurobiology, and educational psychology to create a new discipline focused on the connection between the mind, the brain, and education (Renate Nummela Caine \& Caine, 1991; Dehaene, 2009; Fischer, 2009; Jensen, 2005; Sousa \& Pilecki, 2018; Stern et al., 2005; J. N. Zadina, 2015). This interdisciplinary approach enhances a "deeper knowledge of learning-teaching" to design and direct educational practice and policy (Fischer, 2009; E. P. Jensen, 2008; Schwartz, Hinesley, Chang, \& Dubinsky, 2019).

New brain-imaging technologies such as magnetic resonance imaging (MRI), functional magnetic resonance imaging (fMRI), electroencephalography (EEG), and magneto-encephalography (MEG) show variations in human brain functioning while learning occurs. These imaging technologies have played an important role in the growth of cognitive neuroscience which is fundamental to the emergence of Brain-Based Instruction (G. Caine, Caine, \& Crowell, 1994; Renate Nummela Caine \& Caine, 1991; E. P. Jensen, 2008) and have been influential in evoking changes in existing classroom practices (Renate N Caine \& Caine, 2015; Marope, 2016).

Brain-Based Instruction (BBI), based on neuroscience research, emerged in the early $1980 \mathrm{~s}$ as an alternative teaching strategy (Renate Nummela Caine, Caine, McClintic, \& Klimek, 2015; Jensen, 2005; J. N. Zadina, 2015). BBI is characterized as a student-centered learning method that utilizes the whole brain and takes into account learning disparities between students. BBI is active learning that encourages learners to construct their acquired knowledge in a variety of learning contexts (Renate Nunarela Caine \& Caine, 1994; Renate N Caine \& Caine, 2015). BBI emphasizes the reception, processing, interpretation, storage, retrieval, and connections of information in the brain (E. P. Jensen, 2008; J. N. Zadina, 2015). It is a set of principles and skills that enable students to be more efficient in their learning 
(E. Jensen, 2008). BBI utilizes fundamental knowledge about how different parts of the brain work to improve learning. This knowledge assists instructors in the development, preparation, and delivery of education content in the classroom (Uzezi \& Jonah, 2017; Wolfe, 2010).

Cognizant of the value and significance of BBI, several countries have included BBI into their school curriculum to enrich the learning-teaching process. For example, special education, undergraduate education, and graduate teacher education programs in the United States, offer instruction on BBI (J. D. Connell, 2009). Numerous instructors now apply its principles in their classrooms. Similarly, many instructors and researchers in England are working on BBI (Howard-Jones, 2014). Japan invests considerable resources in brain research and BBI is utilized as an alternative teaching approach in their schools (Eröcal, 2015; United Nations Educational \& Organization, 2015). European Union countries, such as Germany, Norway, the Netherlands, Finland, and others, have included BBI in their schools (D. J. Connell, 2005; Ferrari \& Vuletic, 2010; Hirsh-Pasek \& Bruer, 2007; Sprenger, 2010). China introduced BBI into its school system as an essential instructional approach (Sharma, 2007; United Nations Educational \& Organization, 2015). Other countries, such as Chile, Turkey, and Thailand are applying BBI educational approaches in their schools (Bowers, 2016; J. D. Connell, 2009; United Nations Educational \& Organization, 2015; Yeung, Goto, \& Leung, 2017).

In the past ten years, the Ethiopian government has made curriculum reform in undergraduate programs a priority and has directed attention to the mode of delivery of learning and the continuous assessment of learning to improve the quality of instruction in Higher Education Institutions (HIE) (Dinsa, Tollessa, Tadesse, \& Ferede, 2014; MoE., 2015). Moreover, the Education and Training Policy of Ethiopia has emphasized improvements in educational facilities, technology, teaching approaches (inquiry, discovery, problem-solving, manipulation of hands-on objects, laboratory experimentation, cooperative learning), materials, environments, practical training, organization, and management as prerequisites for enhancing the quality of the learning-teaching process in HEI (MoE., 1994). As part of this improvement process, students in HEI are expected to learn best by putting their mind and hands into action, by work together with other students, by actively doing experiments, by working experimentally in the field, by making critical observations, and by producing something by themselves rather than depending on ready-made lectures from their instructors (Degago \& Kaino, 2015; Dinsa et al., 2014).

Despite this massive reform effort, substantial numbers of undergraduate learners are not well qualified and suffer unemployment after completing education. This may reflect the low quality of instruction or a low relevance of higher education courses being offered (MoE., 2015). Moreover, 
many Natural and Computational Sciences (NCS) and Engineering instructors in various universities in the country have not shown a change in their instructional methods (MoE., 2015; T. Tadesse, 2015; Tefera Tadesse, Manathunga, \& Gillies, 2018). NCS and Engineering instructors predominantly use traditional teaching methods in their classrooms aimed at the coverage of required content (MoE., 2015a, 2015b). Furthermore, given that BBI is a multifaceted and complex construct, research evidence of its successful classroom use in universities is minimal. Indeed, it is often haphazardly implemented and seems ineffective (MoE., 2015; Tefera Tadesse et al., 2018). Whether this ineffectiveness is linked to a lack of knowledge or a lack of implementation of BBI by NCS and Engineering instructors is not known (T. Tadesse, 2015).

Most studies of BBI have focused on elementary and secondary schools, with little research on colleges. Available studies are generally based on a quasi-experimental research design with small sample sizes and narrow settings and fail to explore the comprehensive nature of BBI (Olaoluwa \& Ayantoye, 2016; Uzezi \& Jonah, 2017; Valizadeh, Liem, Mérillat, Hänggi, \& Jäncke, 2018). There are no scholarly studies, supported by a relevant theoretical perspective and sound empirical evidence, that comprehensively explore how NCS and Engineering instructors in Ethiopian public HEI perceive and implement BBI in the classroom. Thus, this study aims to probe the current status of BBI practice by NCS and Engineering instructors in the Tigray region, Ethiopia. The study raised the following questions:

\section{Research Questions}

1) To what extent do the Natural and Computational Sciences and Engineering instructors in higher education institutions apply BBI in their classrooms?

2) Is there a significant difference in the use of BBI by the Natural and Computational Sciences and Engineering instructors related to Higher Diploma Program training?

3) Is there a significant difference in the use of BBI by Natural and Computational Sciences and Engineering instructors related to the length of teaching experience?

\section{Material and Methods \\ Research Design}

This study used a descriptive survey research design with concurrent mixed (qualitative and quantitative) methods to provide a comprehensive view of BBI practice by Natural and Computational Sciences and Engineering instructor in Ethiopian Higher Education Institutions (EHEI). 


\section{Population and Sampling Method}

Research participants were instructors from the College of Natural and Computational Sciences (CNCS) and the College of Engineering (CE) in EHEI. For the quantitative survey, a total of 512 instructors (292 from NCS and 220 from Engineering) were selected by systematic random sampling. Of the participants, 326 were males and 186 were females. The average age of participants was 35.6 years and ranged between 26 and 56 years. Based on years of teaching experience, 364 instructors had short-teaching experience (less than 11 years), 124 instructors had medium-teaching experience (between 11 and 20 years), and 24 instructors had long-teaching experience (above 20 years). The teaching experience was classified based on ranks set by the Ministry of Education (MoE, 2009). Besides, six senior instructors (three from NCS and three from Engineering) were included for a detailed interview. Table 1 shows the demographic characteristics of the participants.

\section{Instruments of Data Collection Likert Scale}

The Likert scale is a five (or seven) point scale that allows individuals to express ranked agreement or disagreement with a particular statement. It supports the computation of combined scores (sum or mean) from four or more mutually related items (Boone \& Boone, 2012; Subedi, 2016) and parametric statistics such as mean and standard deviation. In this study, twenty Likert scale items were developed to assess the practice of BBI by NCS and Engineering instructors. Items were selected based on brain-based learning principles (Renate Nunarela Caine \& Caine, 1994; E. Jensen, 2008), other related literature, and advice from experts.

This study used factor analysis to identify different components of the scale. The 20 items were allocated into three components of BBI, 'relaxed alertness' (9 items), 'orchestrated immersion' (6 items), and 'active processing' (5 items). Instructors were asked to respond to each item on a fivepoint Likert-scale response ranging from always to never; where always $=5$, often $=4$, sometimes $=3$, rarely $=2$, and never $=1$. The total score ranged from 20 to 100 , with higher scores indicating a more favorable implementation of BBI principles.

\section{Interview}

Semi-structured interviews with instructors in NCS and Engineering were done to explore additional qualitative information about the current learning-teaching process concerning the practices of BBI. The semistructured interview is less hierarchical and gives participants the freedom to describe their beliefs informally. This study used a flexible question structure to allow the interviewee to be comfortable in responding (Kothari, 2004). 
Some direct quotations from respondents were used to verify and validate the study report (Rodrigues, Correia, \& Kozak, 2016).

Table 1: Interviewees' Demographic Characteristics

\begin{tabular}{|c|c|c|c|c|c|c|}
\hline Department & Frequency & Gender & Age & Experience & Qualification & College \\
\hline Mathematics & 1 & Male & 44 & 21 & $\begin{array}{c}\text { PhD (Associate } \\
\text { Professor) }\end{array}$ & CNCS \\
\hline Chemistry & 1 & Male & 38 & 16 & $\begin{array}{l}\text { Lecturer (Assistant } \\
\text { Professor) }\end{array}$ & CNCS \\
\hline Biology & 1 & Female & 36 & 13 & $\begin{array}{c}\text { PhD (Assistant } \\
\text { Professor) }\end{array}$ & CNCS \\
\hline $\begin{array}{l}\text { Civil } \\
\text { Engineering }\end{array}$ & 1 & Male & 40 & 17 & Lecturer & $\mathrm{CE}$ \\
\hline $\begin{array}{l}\text { Electrical } \\
\text { Engineering }\end{array}$ & 1 & Female & 37 & 14 & Lecturer & $\mathrm{CE}$ \\
\hline $\begin{array}{l}\text { Mechanical } \\
\text { Engineering }\end{array}$ & 1 & Male & 35 & 12 & Lecture & $\mathrm{CE}$ \\
\hline
\end{tabular}

Note: CNCS refers to the College of Natural and Computational Sciences; CE refers to the College of Engineering.

\section{Validity and Reliability of Instruments}

A pilot study was conducted to determine the validity and reliability of the survey questionnaire. The relaxed alertness subscale consisted of 9 items $(\alpha=.882)$, the orchestrated immersion subscale consisted of 6 items $(\alpha=.802)$, and the active processing subscale consisted of 5 items $(\alpha=.757)$. The Cronbach's alphas for the overall 20 BBI items were .874. The Cronbach Alpha coefficients of reliability for all the variables showed acceptable internal consistency reliability (Field, 2005).

\section{Methods of Data Analyses}

This study used SPSS 24 to analyze the quantitative data. Before final data analysis, fundamental assumptions (data normality, skewness, and the existence of outliers) were examined. The skewness of distribution for all 20 items was between -1 and 1 . The data were approximately normally distributed, and there were no potential outliers that violate this assumption. This study utilized both descriptive and inferential statistics for quantitative data analysis.

The descriptive statistics used in this study were cumulative percentage, mean, median, and standard deviation. Here, the mean score measures the combined performance of all instructors. However, the median score measures typical instructors' performance. The cumulative percentage used to evaluate the accomplishment of instructors who score 4 or 5 for each item. This result relatively shows a clear picture of how NCS and Engineering instructors apply BBI in their current learning-teaching process. For this 
purpose, the study used the following three performance grading criteria in Table 2 (K. R. Sundaram, 2009).

Table 2: Criteria used for the analysis of BBI practice

\section{Criteria}

\begin{tabular}{lccc} 
Performance Grading & Mean & Median & Cumulative \% \\
\hline Excellent practice & $\geq 3.6$ & $4 \& 5$ & $\geq 80$ \\
Good/Acceptable practice & 2.6 to 3.6 & 3 & 60 to 80 \\
Poor practice/Needs improvement & $<2.6$ & $1 \& 2$ & $\leq 60$ \\
\hline
\end{tabular}

Inferential statistics such as Independent samples t-test and one-way ANOVAs were used. For the third research question, assumptions of independence, normality of data, and homogeneity of variances were checked. After ensuring these fundamental assumptions, One-way ANOVA was used to analyze the third research question. Table 5 shows descriptive statistics and ANOVA tests for HEI instructors' practices of BBI concerning their experiences.

To analyze the qualitative data obtained from each interviewee, first, each word was transcribed and then coded in line with the research questions. Finally, thematic analysis was applied to analyze the qualitative data vis-à-vis the quantitative data.

\section{Results}

This research aimed to explore how NCS and Engineering instructors in EHEI implemented BBI principles in their classrooms. The first research question examined the extent to which NCS and Engineering instructors utilize BBI in their classes. The results are expressed in terms of three fundamental elements of BBI (relaxed alertness, orchestrated immersion, and active processing). Table 3 shows the descriptive statistics for the responses by NCS and Engineering instructors regarding their use of BBI in the classroom.

Table 3: Descriptive statistics of the responses of NCS and Engineering Instructors' practice towards BBI $(\mathrm{N}=512)$

\begin{tabular}{clccc}
\hline Item & \multicolumn{1}{c}{ Statement } & Mean & Median & Cum.\% \\
\hline P1 & Let students assess their learning. & 3.31 & 3 & 36.52 \\
P2 & $\begin{array}{l}\text { Apply one-to-one, small group, and/or whole group } \\
\text { discussion in class. }\end{array}$ & 3.44 & 3 & 44.53 \\
P3 & Let students interact with one another in class. & 3.26 & 3 & 36.72 \\
P4 & Provide students enough time to process information. & 2.08 & 2 & 25.98 \\
P5 & Let students spend time doing practical work. & 2.08 & 2 & 29.3 \\
P6 & Provide students enough exposure to new concepts, & 3.34 & 3 & 39.06 \\
& skills, and facts. & & &
\end{tabular}


P7 Keep students' interest in the class.

P8 Keep students' attention in class.

P9 Let students construct their learning.

\section{Relaxed Alertness}

P15 Let students see the big picture of a concept before breaking it into parts.

P16 Use a multi-sensory environment during instruction.

P17 Let students see interconnected patterns.

P18 Apply multiple forms of assessment.

P19 Apply challenging activities that require critical thinking in class.

P20 Let students associate their previous knowledge with present knowledge.

\section{Orchestrated Immersion}

P10 Apply the integrated learning styles.

P11 Provide students with chances to consolidate and internalize information.

P12 Apply inductive teaching methods.

P13 Apply the analysis and synthesis methods of teaching.

P14 Provide ongoing instant feedback.

\section{Active Processing}

Overall instructors' practice towards BBI

$\begin{array}{lcc}3.40 & 3 & 47.07 \\ 3.14 & 3 & 31.05 \\ 2.42 & 2 & 31.45 \\ \mathbf{2 . 9 4} & \text { SD = .60 } & \\ 3.44 & 3 & 44.14 \\ & & \\ 3.57 & 4 & 60.55 \\ 3.93 & 4 & 85.59 \\ 2.32 & 2 & 40.63 \\ 3.49 & 3 & 60.63 \\ & & \\ 3.45 & 3 & 42.97 \\ & & \\ \mathbf{3 . 3 7} & \text { SD }=\mathbf{. 5 2} & \\ 3.54 & 3 & 62.54 \\ 2.53 & 2 & 39.45 \\ & & \\ 3.79 & 4 & 83.19 \\ 3.76 & 4 & 64.84 \\ 3.53 & 3 & 59.25 \\ \mathbf{3 . 4 3} & \text { SD }=\mathbf{. 5 3} & \\ \mathbf{3 . 2 5} & \text { SD }=\mathbf{. 4 3} & \end{array}$

Note: Cum. \% refers to the cumulative percentage, SD refers to standard deviation.

Descriptive analysis of quantitative data shows the first component of $\mathrm{BBI}$ is relaxed alertness and the mean score value was $2.94(\mathrm{SD}=.60)$. In combined indicators of relaxed alertness, the practice of instructors rated below average, which indicates that instructors apply BBI in their class is poor. For example, the practice of instructors to render enough time for their students to process information, do practical work, and construct their learning is below goal (Table 3).

The interview with instructors showed similar results. The majority of the interviewees confirmed that they are disappointed with the way they apply BBI in their classroom. For example, for the question, "to what extent do instructors apply BBI (relaxed alertness) in their class?" one interviewee from Civil Engineering depicts the situation as:

Honestly speaking, most instructors in the college rely on lengthy lecture method and PowerPoint presentation method. There are on average seventy students in a single class. In this regard, let alone allow every student to assess their learning, it is difficult to apply one-to-one or small group discussion due to such a large class size. In fact, most instructors have tried to assess students' understanding by asking oral questions. 
Similarly, another interviewee from Chemistry Department said:

..., though instructors have tried to enhance students' learning capacity and motivation through peer and group interaction, the laboratory and classroom environment are not comfortable to apply the different components of BBI in the actual class. Students' seating arrangement is in a traditional fixed row armchair. It has not adequate space for learners to move and work in a group. As a result, learners are not willing to do practical activities through group discussion. Especially in the afternoon, learners are inactive due to excessive crowds and sophistication.

The results indicate that instructors are not effectively applying BBI (relaxed alertness). This suggests that the implementation of BBI will require diligent follow-up and continuous support for effective implementation.

On the second component of BBI, orchestrated immersion, the mean score value was $3.37(\mathrm{SD}=.52)$, suggesting that instructor practice towards orchestrated immersion rated above average (Table 3). It seems to be reasonable but not to its high quality. Indeed, the middle score indicates instructors use (sometimes) various indicators of orchestrated immersion in the learning-teaching process. For example, though orchestrated immersion focuses on applying challenging activities that require critical thinking and multiple forms of assessment, the quantitative results indicate that instructors poorly utilize strategies in their class. One interviewee from the Mathematics Department noted that:

Most of the time, students assigned to the department are less interested and relatively weak in their academic performance. They are not willing and capable of doing challenging activities. They always expect everything from their instructors. As a result, most instructors do not apply challenging tasks and variant forms of assessment.

On the third component of BBI, active processing, the mean score value was $3.43(\mathrm{SD}=.53)$. Though the mean score is above average and seems acceptable, instructors are less effective in providing enough opportunities for their learners to consolidate and internalize information. As an interviewee from Mechanical Engineering expressed:

..., Instructors have tried to apply the different techniques of BBI in the actual learning-teaching process. But most instructors do not effectively practice the strategy in the class for various reasons. For instance, the time allocated and the content of the course are not in balance. Instructors encounter 
a shortage of time to enable students to consolidate the different concepts with their real experiences. Besides, considerable numbers of instructors do not provide continuous instant feedback. In this case, learning might not occur as intended in the curriculum. Hence, several students fail to comprehend the fundamental concepts of the course.

Few instructors showed excellent usage of BBI principles in their classes (Figure 1). Taking cumulative percentage as measurement, only $10 \%$ of the instructors had an excellent performance of BBI. And 20\% of them had good/acceptable performance. Significantly, the majority (70\%) of instructors had poor performance towards utilizing BBI principles in the classroom.

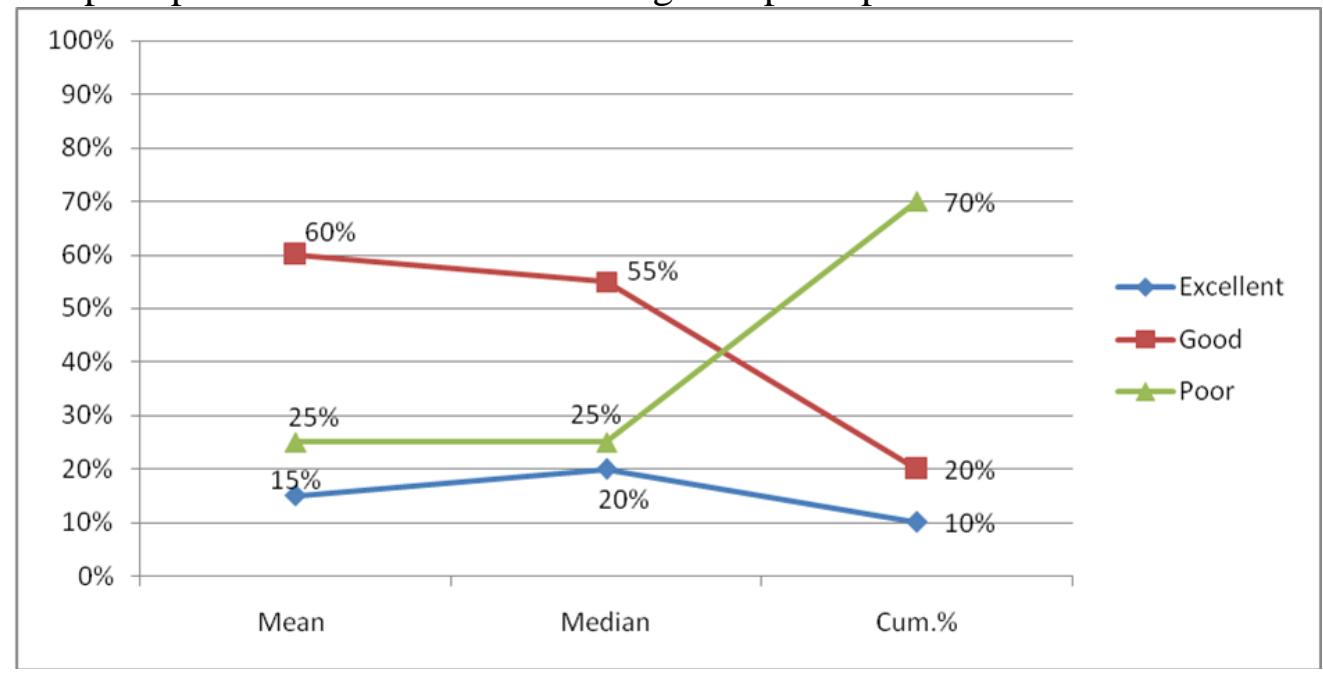

Figure 1: The extent of the overall instructors' practice towards BBI.

Consistent with the above result, an instructor from Electrical Engineering described that:

..., HDP training is offered to instructors aimed at how to use the different active learning methods (such as peer discussion, group discussion, inquiry method, laboratory method, a problem-solving method, etc.) in the actual class. However, most instructors usually choose to use the conventional lecture method and PowerPoint in the learning-teaching process rather than the principles of BBI. This is because of the large class size and the insufficient time allotted and the large content of the course. Most of the time, the emphasis was given to course coverage rather than learners' learning. 
On the other hand, an instructor from the Biology Department expressed that: Most of the time, in the department of Biology, instructors prepare lessons in a way that accommodates the relaxed alertness, orchestrated immersion, and active processing. For example, at the beginning of the class, instructors use the brain-storming method so that students think about the new lesson and try to associate it with the previous knowledge. During the actual learning-teaching process, peer and group discussion were the most commonly used methods. Students were provided with reflection time to comprehend the main concepts of the lesson. And, finally, instructors provide constructive feedback and make a summary.

Our second research question addressed whether instructors who had taken the Higher Diploma Program (HDP) were more likely to implement BBI in the classroom. The finding showed that NCS and Engineering instructors who had taken the HDP training were significantly more likely to implement all components of BBI in their classes (relaxed alertness ( $t$-test, $t=7.678$, $d f=510, p<.001)$, orchestrated immersion $(t=4.540, d f=510, p<.001)$, and active processing $(t=6.008, d f=510, p<.001))$ than instructors without HDP training (Table 4). Inspection of the overall BBI practices of the two groups indicates that the average score of the HDP trained instructors (3.54) is significantly higher than the untrained instructors (3.22). The difference between the means is .32. The corresponding effect $\operatorname{size}^{1}(d)$ is approximately .803, larger than a typical sized "effect" (Cohen 1988).

${ }^{1}$ The $d$ family of effect size measures. The d family focuses on magnitude of difference rather than strength of association. If one compares two groups, the effect size (d) can be computed by subtracting the mean of the second group from the mean of the first group and dividing by the pooled standard deviation of both groups. $d=\frac{M_{1}-M_{2}}{S D}$ for equal $n s$ and $d=\frac{M_{1}-M_{2}}{\sqrt{\frac{\left(n_{1}-1\right) S D_{1}^{2}+\left(n_{2}-1\right) S D_{2}^{2}}{n_{1}+n_{2}-2}}}$ for unequal $n$ s. 
Table 4: Descriptive statistics and t-test for the responses of NCS and Engineering Instructors' practices on BBI concerning HDP training

\begin{tabular}{lccccccc}
\hline Components & HDP training & $\mathbf{N}$ & Mean & SD & $\boldsymbol{t}$ & $\boldsymbol{d} f$ & $\boldsymbol{P}$ \\
\hline Relaxed Alertness & & & & & & & \\
& Yes & 335 & 3.39 & .5759 & 7.678 & 510 & .000 \\
Orchestrated Immersion & No & 177 & 2.98 & .5612 & & & \\
& Yes & 335 & 3.63 & .5145 & 4.540 & 510 & .000 \\
Active Processing & No & 177 & 3.41 & .5158 & & & \\
& Yes & 335 & 3.72 & .5127 & 6.008 & 510 & .000 \\
Overall BBI Practices & No & 177 & 3.43 & .5039 & & & \\
& Yes & 335 & 3.54 & .4109 & 8.625 & 510 & .000 \\
& No & 177 & 3.22 & .3745 & & & \\
\hline
\end{tabular}

The third research question addressed whether the length of teaching experience influenced the use of BBI principles in the classroom. Table 5 shows that the mean response values of NCS and Engineering instructors with long teaching experience had the highest responses on all sub-components of BBI: relaxed alertness, orchestrated immersion, active processing, as well as on the overall practice of BBI.

Table 5: Descriptive statistics and One-way ANOVA of NCS and Engineering instructors' practice on BBI concerning teaching experience

\begin{tabular}{lllllll}
\hline Components & Experience & N & Mean & SD & $\boldsymbol{F}$ & $\boldsymbol{p}$ \\
\hline Relaxed Alertness & Short & 364 & 3.1685 & .59487 & 12.124 & .000 \\
& Medium & 124 & 3.4346 & .60428 & & \\
& Long & 24 & 3.5231 & .39925 & & \\
Orchestrated Immersion & Short & 364 & 3.5385 & .52767 & 1.100 & .334 \\
& Medium & 124 & 3.6102 & .53928 & & \\
& Long & 24 & 3.6319 & .37744 & & \\
Active Processing & Short & 364 & 3.5687 & .52002 & 7.268 & .001 \\
& Medium & 124 & 3.7613 & .54619 & & \\
Overall BBI Practices & Long & 24 & 3.7667 & .36673 & & \\
& Short & 364 & 3.3795 & .42296 & 11.853 & .000 \\
& Medium & 124 & 3.5690 & .42554 & & \\
& Long & 24 & 3.6167 & .26237 & & \\
\hline
\end{tabular}

On the other hand, instructors with short teaching experience had the lowest response values in all the sub-components of BBI and the overall practice. Instructors with medium teaching experience had the least responses on relaxed alertness. Length of teaching experience did not influence the use of orchestrated immersion in the classroom (Table 5, One-way ANOVA, $F(2,509)=1.100, p=.334)$. NCS and Engineering instructors of short, medium, and long teaching experiences had similar responses on the orchestrated immersion items. The groups differed for relaxed alertness $(F(2,509)=12.124$, $p<.001)$, active processing $(F(2,509)=7.268, p=.001)$, and on the overall BBI 
practice $(F(2,509)=11.853, p<.001)$. The results indicate that duration of teaching experience has a positive impact on the use of BBI as different groups depicted variations in their level of practicing BBI. To further explore post hoc group differences, tests of homogeneity were done.

Table 6: Test of Homogeneity of Variances of groups based on teaching experience

\begin{tabular}{lcccc}
\hline Variables & $\begin{array}{c}\text { Levene } \\
\text { Statistic }\end{array}$ & df1 & df2 & Sig. \\
\hline Relaxed Alertness & 2.151 & 2 & 509 & .117 \\
Orchestrated Immersion & 1.604 & 2 & 509 & .202 \\
Active Processing & 3.418 & 2 & 509 & .034 \\
Overall BBI practice & 1.998 & 2 & 509 & .137 \\
\hline
\end{tabular}

The Levene's test of homogeneity of variances (Table 6) was used to check the assumption of equal group variances. The Levene's test was not statistically significant for relaxed alertness $(p=.117)$ and overall BBI practice $(p=.137)$, suggesting that equal variances could be assumed and that post hoc comparisons could be done using Tukey HSD. However, for active processing $(p=.034)$, Levene's test was significant and the assumption of equal variances was violated. For active processing, equal variances were not assumed, and post hoc comparisons were made using Games-Howell.

Table 7: Post hoc Analysis of Mean scores of groups based on teaching experience

\begin{tabular}{|c|c|c|c|c|c|c|}
\hline & Dependent Variable & $\begin{array}{c}\text { (I) } \\
\text { Experience } \\
\text { category }\end{array}$ & $\begin{array}{c}(\mathrm{J}) \\
\text { Experience } \\
\text { category }\end{array}$ & $\begin{array}{c}\text { Mean } \\
\text { Difference } \\
(\mathrm{I}-\mathrm{J})\end{array}$ & $\begin{array}{l}\text { Std. } \\
\text { Error }\end{array}$ & Sig. \\
\hline \multirow[t]{6}{*}{ Tukey HSD } & \multirow[t]{6}{*}{ Relaxed Alertness } & \multirow[t]{2}{*}{ Short } & Medium & $-.26609^{*}$ & .06132 & .000 \\
\hline & & & Long & $-.35465^{*}$ & .12429 & .012 \\
\hline & & \multirow[t]{2}{*}{ Medium } & Short & $.26609^{*}$ & .06132 & .000 \\
\hline & & & Long & -.08856 & .13152 & .779 \\
\hline & & \multirow[t]{2}{*}{ Long } & Short & $.35465^{*}$ & .12429 & .012 \\
\hline & & & Medium & .08856 & .13152 & .779 \\
\hline \multirow[t]{6}{*}{ Tukey HSD } & \multirow[t]{6}{*}{ Overall BBI practice } & \multirow[t]{2}{*}{ Short } & Medium & $-.18942^{*}$ & .04343 & .000 \\
\hline & & & Long & $-.23713^{*}$ & .08802 & .020 \\
\hline & & \multirow[t]{2}{*}{ Medium } & Short & $.18942^{*}$ & .04343 & .000 \\
\hline & & & Long & -.04772 & .09314 & .865 \\
\hline & & \multirow[t]{2}{*}{ Long } & Short & $.23713^{*}$ & .08802 & .020 \\
\hline & & & Medium & .04772 & .09314 & .865 \\
\hline \multirow[t]{6}{*}{ Games-Howell } & \multirow[t]{6}{*}{ Active Processing } & \multirow[t]{2}{*}{ Short } & Medium & $-.19261^{*}$ & .05611 & .002 \\
\hline & & & Long & $-.19799^{*}$ & .07967 & .048 \\
\hline & & \multirow[t]{2}{*}{ Medium } & Short & $.19261^{*}$ & .05611 & .002 \\
\hline & & & Long & -.00538 & .08950 & .998 \\
\hline & & \multirow[t]{2}{*}{ Long } & Short & $.19799^{*}$ & .07967 & .048 \\
\hline & & & Medium & .00538 & .08950 & .998 \\
\hline
\end{tabular}

Post hoc comparison tests indicate which specific group means are different from others. For relaxed alertness, the mean practice score is 3.1685 
for instructors with short teaching experience, 3.4346 for instructors who have medium teaching experience, and 3.5231 for instructors who have long teaching experience (Table 5). Concerning instructors' use of relaxed alertness in their instruction, in Table 7, Post hoc Tukey HSD tests indicate that the short and medium experienced group differed significantly in the practice of relaxed alertness $(p<.001)$. That is, instructors with medium teaching experience applied relaxed alertness in their class better than shortly experienced instructors. Likewise, the short- and long-experienced group differed significantly in applying relaxed alertness $(p=.012)$. Long experienced instructors applied the method better than shortly experienced instructors. However, there was no significant difference between the medium and long experienced instructors in applying relaxed alertness in their classroom $(p=.779)$.

Regarding variable active processing, post hoc comparison GamesHowell tests indicate that the mean score practice of instructors who had short teaching experience was 3.5687. The mean score practice of the instructors with medium teaching experience was 3.7613 and for the long teaching experience, the mean score practice was 3.7667 (Table 5). In this regard, Post hoc comparison Games-Howell tests show that instructors with short experience differed significantly in their practice $(p=.002, d=-.37)$ from the medium experienced instructors (Table 7). Similarly, instructors with short teaching experience had a significant difference in their practice $(p=.048, d=-$ .39) as compared to the instructors with long-year experience. On the contrary, there was no significant difference between the medium and the long experienced instructors' practice $(p=.998, d=-.01)$, which implies that instructors with medium and long-years of teaching experience did not vary in their learning-teaching practice towards active processing. However, shortexperienced instructors apply less active processing as a strategy in their instruction as compared to medium- and long-experienced instructors.

As to overall instructor BBI practice, post hoc comparison Tukey HSD tests indicate that the mean score practice of short teaching experience instructors was 3.3795. The mean score practice of medium teaching experience instructors was 3.569. And the mean score practice of the longteaching experience instructors was 3.6167 (Table 5). In this regard, the result in Table 7, post hoc comparison Tukey HSD tests show that shortly experienced instructors differed significantly in their practice $(p<.001, d=-$ $.45)$ from medium experienced instructors. Similarly, instructors with short experience had a significant difference in their practice $(p=.020, d=-.57)$ as compared to instructors with long-year experience. On the contrary, there was no significant difference between medium and long experienced instructors' practice $(p=.865, d=-.12)$. This implies that medium, as well as long experienced instructors, did not vary significantly in applying BBI in their 
learning-teaching process. However, short experience instructors apply BBI less than medium and long experienced instructors and the variation is statistically significant.

\section{Discussion}

The goal of this study is to examine how NCS and Engineering instructors in EHEI practice BBI in their classrooms. Specifically, this paper examined the extent to which instructors used elements of BBI (relaxed alertness, orchestrated immersion, and active processing) in their learningteaching process. It also investigated how HDP training and years of teaching experience influenced the use of BBI in the classroom.

Prior work has indicated that BBI is an effective teaching method for teaching in NCS and Engineering and helps instructors to improve their teaching practices at all grade levels and grants improved learning ability and skills to learners (Jensen, 2005; E. P. Jensen, 2008; Ozden \& Gultekin, 2008; Shabatat \& Al-Tarawneh, 2016). According to Renate Nunarela Caine and Caine (1994), effective learning-teaching occurs when instructors utilize fundamental components of BBI in an organized and integrated manner. Besides, designing appropriate lessons based on techniques of BBI and delivering them in the learning-teaching process possibly result in improving the learning ability of learners (Akyürek \& Afacan, 2013).

In general, the finding of this study indicated that an inadequate practice of BBI in EHEI. Quantitative results show that most instructors did not apply the basic elements of BBI in their classrooms. Instructors did not provide enough time for their students to process information, do practical work, construct their learning, and consolidate and internalize information. This signifies that when instructors apply strategies that do not support relaxed alertness, orchestrated immersion, and active processing, the learningteaching process does not make sense for learners and hence do not make meaningful learning (Blakemore \& Frith, 2005). Consistent with the quantitative results of this study, interviews indicated that most instructors use the traditional lecture method and PowerPoint presentations instead of BBI. Due to this fact, learners do not get enough time to comprehend the basic concepts of the lesson (E. P. Jensen, 2008; Radin, 2009). Consequently, learners do not make connections with their prior knowledge (Renate N Caine \& Caine, 2015). Jensen also confirmed that whenever instructors do not provide appropriate brain-break/waiting time/, learners do not conceptualize and process new learning effectively.

In congruence with the above, findings showed that the existing large class size and the unpleasant classroom setting influence instructors from using effective BBI. Learners' movement and interaction were limited. Due to this fact, instructors face problems to apply peer or/and group discussions. If 
there is no free movement and interaction among learners and learners-toinstructor during the instructional period, effective learning does not exist (Renate Nummela Caine et al., 2005; D'Amato \& Wang, 2015; Jensen, 2016; Wilmes, Harrington, Kohler-Evans, \& Sumpter, 2008). This is because, appropriate movement is an attribute of BBI that facilitates learners' learning (J. D. Connell, 2009; E. Jensen, 2008) and enables better understanding and connections (E. Jensen, 2008; Radin, 2009). This signifies that NCS and Engineering instructors in EHEI do not execute BBI as the demand of curriculum and this leads to deteriorating students' learning. Thus, it demands further improvement.

Regarding the effect of HDP training, its central goal is to improve the overall quality of science and education in higher institutions. This training program equips each instructor with effective teaching strategies (such as active learning, cooperative learning, problem-solving, etc.), assessment methods, and action research that focus on resolving problems of classroom teaching (the Federal Democratic Republic of Ethiopia, 2004). In this intention, the study explored whether or not there is a statistically significant difference in the application of BBI in EHEI between trained and untrained NCS and Engineering instructors. In this regard, the finding of the study shows that trained instructors implement BBI more than untrained instructors. The effect size of the mean difference between the two groups was large, which indicates that HDP training was helpful to practice/use different elements of BBI in an effective manner in the actual classroom. In support of this finding, Tesfaye (2017) confirms that HDP training enables instructors to enrich their pedagogical knowledge and skills that are helpful for effective BBI practices in their class. In line with this, Morka (2019) suggested that HDP training has had a significant effect on the learning-teaching process of higher education institutions. It has enabled instructors to distinguish appropriate teaching strategies among others and apply them in their classes. Several researchers emphasized the value of HDP training that helps instructors to use components of BBI in organized and integrated manner to meet individual student needs and improve their practical learning (the Federal Democratic Republic of Ethiopia, 2004). Therefore, the study signifies that HDP training has significant value for NCS and Engineering instructors in EHEI to improve their BBI knowledge and classroom practices.

Regarding the influence of instructors' teaching experience towards the effective use of BBI, the finding shows that teaching experience has a statistically significant positive effect on the practice of BBI in the actual classroom. The ANOVA test results depict the existence of variations in the use of BBI in the learning-teaching process. To this end, post hoc comparison Tukey HSD tests indicate that NCS and Engineering instructors with medium and long years of teaching experience apply BBI better than the shortly 
experienced instructors. However, there was no statistically significant difference in the use of BBI between the instructors with medium and long years of teaching experience.

Similarly, the finding of this research indicates that effect size (d) for shortly experienced instructors $(\mathrm{d}=-.45)$ is significantly less than that of medium years of experience. Similarly, effect size (d) for shortly experienced instructors $(\mathrm{d}=-.57)$ is significantly less than those with long years of teaching experience. It implies that as instructors become more experienced, they tend to apply more BBI in class. In support of this finding, Wolters and Daugherty (2007) suggested that experienced instructors use BBI more effectively as compared to instructors with relatively short teaching experiences. Some researchers also confirmed this positive relationship between teaching experiences and effective BBI classroom practice (Galotti, 2014; Morris, 2010; J. Zadina, 2014). Other researchers also emphasized the direct positive effect of teaching experience and their use of BBI in their teaching (Galotti, 2014; Morris, 2010; J. Zadina, 2014). In line with this, research made by Kini and Podolsky (2016) indicated that most instructors increase usage of BBI with long teaching experiences.

Following the investigation of the variations in teaching experience and the act of applying the core elements of BBI, Morris (2010) assured that instructors with long years of teaching experience (above 21 years) effectively use elements of BBI than instructors with fewer years (less than ten years). In line with the above findings, Galva' $n$ (2010) and J. Zadina (2014), brain-based experts, have asserted that effective learning-teaching occurs as a result of acquiring tangible experience or frequent practice of activities related to different parts of the brain. Indeed, the more experienced instructors obtain, the more relaxed in adopting and applying the elements of BBI (Galotti, 2014; J. Zadina, 2014). However, other researchers have come up with a negative association between teaching experiences and the effectiveness of their BBI application in the classroom (Klinek, 2009; Mansy, 2014; Wachob, 2012).

All in all, this study reveals that the practice of BBI in EHEI is not satisfactory. Yet, the study indicated the possibility of effective utilization of BBI by enhancing HDP training and creating a conducive working environment for instructors to stay in their profession for a long period.

\section{Conclusion}

Currently, Ethiopian Higher Education Institutions (EHEI) aggressively work to improve the quality of education with special due attention to the learning-teaching process. BBI is one of the effective methods of teaching that help to assure the quality of education at HEI by equipping students with intended knowledge and skills. To this end, this study aimed to examine the extent to which NCS and Engineering instructors apply BBI with 
due attention to the essential components (such as relaxed alertness, orchestrated immersion, as well as active processing) in their class. The overall findings of this study show that majority of instructors did not apply BBI effectively in the learning-teaching process as desired. The reason is that most instructors did not provide ample time for their learners to do practical activities, process information, and construct their learning. The instructors also did not regularly let learners work in pairs/groups and apply multiple forms of assessment. Instead, most of the instructors were commonly applying the traditional lecture method and PowerPoint presentation. The classroom settings were not in general conducive to carry on BBI. Under such conditions, it is hard for learners to make real connections and internalize different concepts they learned.

On the other side, even though the findings of the study show instructors' poor practice in using BBI, the application of BBI in class was found to vary based on HDP training. The trained instructors apply BBI significantly better than untrained instructors. Successful HDP training enables university instructors to use BBI in class with confidence. And the fact that trained instructors use BBI more possibly indicates the importance of BBI cognition, which means instructors should keep on learning the emerging knowledge about brain research in NCS and Engineering. Only enough BBI knowledge can make instructors take action in class.

Moreover, findings show that the presence of variation in using BBI between experienced and inexperienced instructors. The medium, as well as long year, experienced instructors use BBI in class significantly better than shortly experienced instructors. This implies that as instructors gain experience, they improve their learning-teaching process and hence learners learning.

Thus, the findings of this study highlight that HEI has to do a lot on NCS and Engineering instructors to improve their knowledge and skills of BBI to practice the instruction effectively in the learning-teaching process. Universities should establish a favorable classroom environment for instructors as well as learners to realize effective learning-teaching through BBI. Training instructors on how to create real experiences that enable learners to master what they are learning about by fieldwork and practical attachment with nearby small scale industries is paramount important. Transforming the learning-teaching process into an interactive environment through technology such as television, videos, virtual, and carefully planned activities that empower learners to design and create their learning is essential.

It is also crucial to strengthen HDP training and support instructors through on-job training to excel their fundamental knowledge of BBI that could help them to apply BBI in their class. Besides, continuous follow-up and motivation are indispensable for instructors to stay in their careers for a 
substantial period and improve the quality of learning-teaching practice through BBI.

\section{Limitations and suggestions for future research}

The number of studies carried on about the practice of BBI is very limited in Ethiopian Higher Education Institutions and other developing countries. Indeed, this study, despite its contributions to current literature, has some limitations. It is limited to three public universities in the Tigray region, Ethiopia. Moreover, it only deals with NCS and Engineering instructors in HEI. In this case, the information obtained might not be sufficient to make general conclusions about every university in Ethiopia and other similar universities in developing countries.

On top of the above points, this study gathered data only from questionnaires and interviews with instructors. Further, studies in this regard may include comprehensive classroom observation and focus group discussions with students on how instructors use the fundamental components of BBI in the learning-teaching process. Future research on the extent to which instructors apply BBI in their class might need to include other variables such as instructors' knowledge of BBI, perceptions towards BBI, students' academic achievement, availability of instructional resources, and institutional leadership support. Indeed, this can help to obtain more valuable information and a deep understanding of the big picture of the use of BBI in EHEI.

\section{References:}

1. Akyürek, E., \& Afacan, Ö. (2013). The effect of brain-based learning approach which applied to 8th-grade science and technology classes on students' academic achievement. The Journal of Academic Social Science Studies, 6(1), 75-98.

2. Blakemore, S.-J., \& Frith, U. (2005). The learning brain: Lessons for education: Blackwell publishing.

3. Boone, H. N., \& Boone, D. A. (2012). Analyzing Likert data. Journal of extension, 50(2), 1-5.

4. Bowers, J. S. (2016). Psychology, not educational neuroscience, is the way forward for improving educational outcomes for all children: Reply to Gabrieli (2016) and Howard-Jones et al.(2016).

5. Caine, G., Caine, R. N., \& Crowell, S. (1994). Mind shifts: A brainbased process for restructuring schools and renewing education: Zephyr Press.

6. Caine, R. N., \& Caine, G. (1991). Making connections: Teaching and the human brain. New York.

7. Caine, R. N., \& Caine, G. (1994). Making connections. Teaching and the human brain. Parsippany: NJ: Dale Seymour Publications. 
8. Caine, R. N., \& Caine, G. (2015). Brain/mind principles of natural learning.

9. Caine, R. N., Caine, G., McClintic, C., \& Klimek, K. (2005). 12 brain/mind learning principles in action: The field book for making connections, teaching, and the human brain: Corwin Press.

10. Caine, R. N., Caine, G., McClintic, C., \& Klimek, K. J. (2015). 12 Brain/Mind Learning Principles in Action: Teach for the Development of Higher-Order Thinking and Executive Function: Corwin Press.

11. Cohen, J. (1988). Statistical Power Analysis for the Behavioral Sciences. 2nd eds. Hillsdale, NJ: Lawrence Erlbaum Associates.

12. Connell, D. J. (2005). Brain-based strategies to reach every learner: Recording for the Blind \& Dyslexic.

13. Connell, J. D. (2009). The global aspects of brain-based learning. Educational Horizons, 88(1), 28-39.

14. D'Amato, R. C., \& Wang, Y. Y. (2015). Using a Brain-Based Approach to Collaborative Teaching and Learning with Asians. New Directions for Teaching and Learning, 2015(143), 41-60.

15. Degago, A. T., \& Kaino, L. M. (2015). Towards student-centered conceptions of teaching: the case of four Ethiopian universities. Teaching in Higher Education, 20(5), 493-505.

16. Dehaene, S. (2009). Reading in the Brain: The science and evolution of a human invention: Viking.

17. Dinsa, F., Tollessa, B., Tadesse, K., \& Ferede, B. (2014). Assessment of the Implementation Status of the Nationally Harmonized Competence-Based Modular Curricula in Ethiopian Public Universities. Education Strategy Center, Addis Ababa.

18. Eröcal, D. (2015). UNESCO Science Report: Towards 2030: Paris: United Nations Educational, Scientific, and Cultural Organization.

19. The Federal Democratic Republic of Ethiopia, F. (2004). Report of the federal government on the development of education in Ethiopia to UNESCO forty-seven session of the international education conference. 8-11 September 2004, Geneva, Switzerland.

20. Ferrari, M., \& Vuletic, L. (2010). Developmental Relations among Mind, Brain and Education: Essays in Honor of Robbie Case: Springer.

21. Field, A. (2005). Exploratory factor analysis. Discovering statistics using SPSS, 619-680.

22. Fischer, K. W. (2009). Mind, brain, and education: building a scientific groundwork for learning and teaching1. Mind, Brain, and Education, 3(1), 3-16.

23. Galotti, K. (2014). Cognitive Psychology: In and Out of the Laboratory (Fifth): Los Angeles: SAGE. 
24. Hirsh-Pasek, K., \& Bruer, J. T. (2007). The brain/education barrier. Science, 317(5843), 1293-1293.

25. Howard-Jones, P. A. (2014). Neuroscience and education: myths and messages. Nature Reviews Neuroscience, 15(12), 817-824.

26. Jensen, E. (2005). Teaching with the brain in mind: ASCD.

27. Jensen, E. (2008). Brain-based learning: The new paradigm of teaching: Corwin Press.

28. Jensen, E. (2016). Poor students, rich teaching: Mindsets for change: Solution Tree Press.

29. Jensen, E. P. (2008). A fresh look at brain-based education. Phi Delta Kappan, 89(6), 408-417.

30. K. R. Sundaram, S. N. D. a. V. S. (2009). "Medical Statistics: Principles \& Methods," BI Publications Pvt. Ltd., New Delhi.

31. Kini, T., \& Podolsky, A. (2016). Does teaching experience increase teacher effectiveness? A Review of the Research, 1-72.

32. Klinek, S. R. (2009). Brain-based learning: Knowledge, beliefs, and practices of the college of education faculty in the Pennsylvania state system of higher education. The Indiana University of Pennsylvania.

33. Kothari, C. R. (2004). Research methodology: Methods and techniques: New Age International.

34. Mansy, D. L. (2014). Brain-Based Learning: K-12 Teachers' Preferred Methods of Science Instruction.

35. Marope, P. (2016). Brain science, education, and learning: Making connections: Springer.

36. MoE, F. (2009). Curriculum Framework for Ethiopian Education (KG-Grade 12).

37. MoE. (1994). Education and Training Policy. Addis Ababa. Addis Ababa: Berhanena Selam Printing Enterprise.

38. MoE. (2015). Education Sector Development Programme V (ESDP V): Programme Action Plan. Addis Ababa: Federal Ministry of Education

39. MoE. (2015a). Education Sector Development Program V (ESDP V) 2015/162019/20 G.C. Addis Ababa.: Ministry of Education.

40. MoE. (2015b). Education Statistics Annual Abstract 2006 E.C (2013/2014), Education Management Information System (EMIS) and ICT Directorate. Viewed October 9, 2016, at www.moe.gov.et.

41. Morka, A. (2019). Assessing the Effects of Higher Diploma Program (HDP) Training on the Teaching-Learning Process in Assossa University.

42. Morris, L. T. (2010). Brain-based learning and classroom practice: A study investigating instructional methodologies of urban school teachers: Arkansas State University. 
43. Olaoluwa, S. A., \& Ayantoye, C. A. (2016). Impact of brain-based instructional strategy on academic performance of deaf students in mathematics in Oyo School of Handicapped, Nigeria. World, 3(2).

44. Ozden, M., \& Gultekin, M. (2008). The effects of brain-based learning on academic achievement and retention of knowledge in a science course. The Electronic Journal for Research in Science \& Mathematics Education.

45. Radin, J. L. (2009). Brain-compatible teaching and learning: Implications for teacher education. Educational Horizons, 40-50.

46. Rodrigues, A. I., Correia, A., \& Kozak, M. (2016). Exploring the benefits of using a mixed-methods approach in destination image studies. Qualitative Research Journal, 4(5), 159-181.

47. Schwartz, M. S., Hinesley, V., Chang, Z., \& Dubinsky, J. M. (2019). Neuroscience knowledge enriches pedagogical choices. Teaching and Teacher Education, 83, 87-98.

48. Shabatat, K., \& Al-Tarawneh, M. (2016). The Impact of a TeachingLearning Program Based on a Brain-Based Learning on the Achievement of the Female Students of 9th Grade in Chemistry. Higher Education Studies, 6(2), 162-173.

49. Sharma, Y. (2007). "Mental Exercise: The Appliance of Neuroscience. Theory in Education Is Taking Off." South China Morning Post.

50. Sousa, D. A., \& Pilecki, T. (2018). From STEM to STEAM: Braincompatible strategies and lessons that integrate the arts: Corwin Press.

51. Sprenger, M. (2010). Brain-based teaching in the digital age: ASCD.

52. Stern, Y., Habeck, C., Moeller, J., Scarmeas, N., Anderson, K. E., Hilton, H. J., . . . Van Heertum, R. (2005). Brain networks associated with a cognitive reserve in healthy young and old adults. Cerebral cortex, 15(4), 394-402.

53. Subedi, B. P. (2016). Using Likert type data in social science research: Confusion, issues, and challenges. International journal of contemporary applied sciences, 3(2), 36-49.

54. Tadesse, T. (2015). Quality Assurance in Higher Education in Ethiopia: Boon or Bandwagon in Light of Quality Improvement? Journal of Higher Education in Africa, 12(2), pp. 131-57.

55. Tadesse, T., Manathunga, C. E., \& Gillies, R. M. (2018). Making sense of quality teaching and learning in higher education in Ethiopia: Unfolding existing realities for future promises. Journal of University Teaching \& Learning Practice, 15(1), 4.

56. Tesfaye, A. (2017). Exploring the Implementation and Opportunities of HDP Program for Class Room Instruction, The Case of Dire Dawa University. International Journal of Social Sciences \& Educational Studies, 4(1), 49. 
57. United Nations Educational, S., \& Organization, C. (2015). Unesco science report: Towards 2030: Unesco Paris.

58. Uzezi, J. G., \& Jonah, K. J. (2017). Effectiveness of brain-based learning strategy on students' academic achievement, attitude, motivation, and knowledge retention in electrochemistry. Journal of Education, Society and Behavioural Science, 1-13.

59. Valizadeh, S. A., Liem, F., Mérillat, S., Hänggi, J., \& Jäncke, L. (2018). Identification of individual subjects based on their brain anatomical features. Scientific reports, 8(1), 1-9.

60. Wachob, D. A. (2012). Public school teachers' knowledge, perception, and implementation of brain-based learning practices: Indiana University of Pennsylvania.

61. Wilmes, B., Harrington, L., Kohler-Evans, P., \& Sumpter, D. (2008). Coming to our senses: Incorporating brain research findings into classroom instruction. EDUCATION-INDIANAPOLIS THEN CHULA VISTA-, 128(4), 659.

62. Wolfe, P. (2010). Brain matters: Translating research into classroom practice: ASCD.

63. Wolters, C. A., \& Daugherty, S. G. (2007). Goal structures and teachers' sense of efficacy: Their relation and association to teaching experience and academic level. Journal of educational psychology, 99(1), 181.

64. Yeung, A. W. K., Goto, T. K., \& Leung, W. K. (2017). The changing landscape of neuroscience research, 2006-2015: a bibliometric study. Frontiers in neuroscience, 11, 120.

65. Zadina, J. (2014). Multiple pathways to the student's brain: Energizing and enhancing instruction: John Wiley \& Sons.

66. Zadina, J. N. (2015). The emerging role of educational neuroscience in education reform. Psicología Educativa, 21(2), 71-77. 